\title{
Impact of Social Capital Empowerments on the Businesses Success among the Micro and Small-Scale Tourism Entrepreneurs in Sri Lanka
}

\author{
G.T.W. Sriyani \\ Department of Management and Entrepreneurship \\ Faculty of Management and Finance \\ University of Ruhuna \\ SRI LANKA. \\ gtwasanthas@ badm.ruh.ac.lk
}

\begin{abstract}
This paper aims to reveal the impact of social capital which was empowered by Community Based Tourism projects on the business success of micro and small-scale tourism entrepreneurs (MSSTEs) in rural tourism destinations and to determine is there any distinction of the variation created in the business success by the construct of social capital between the MSSTES who were empowered and who were not empowered. Further, determining of which type of social capital either structural or cognitive does affect highly on the business success was focused. Positivism research approach applied and a sample of MSSTEs in rural tourism destinations from two provinces from Sri Lanka was selected. A pre-tested structured questionnaire was used for primary data collection. Three hypotheses were formulated and tested to reveal the impact of social capital on business success. Independent sample T-Test, correlation and multiple regression analysis were applied to test the hypotheses. Findings revealed that social capital affect significantly on creating a variance in business success. Both structural and cognitive social capital affect significantly on the business success while structural capital shows more power to create a variance on business success than cognitive social capital. This implies that tangible social capital attributes such as well-functioning of community associations, strong interpersonal and institutional networks, regular gathering, etc. are perceived as very important for business success. Also, cognitive type social capital such as shared vision, values and norms, trustworthiness, equality in sharing resources and benefits, etc. creates a significant impact on the business growth.
\end{abstract}

Keywords:- Business Success, Cognitive social capital, Community Based Tourism Projects, Micro and Small-Scale Tourism Entrepreneurs, Structural social capital 


\section{INTRODUCTION}

In the world context, community involvement in tourism businesses is gradually increasing with the demand shifts happened from "Mass Tourism" which focuses on 3Ss concepts (Sun, Sea and Sand) towards "Niche Tourism" which focuses on nature, culture and people. With this movement, many untouched and under-developed areas have been identified as attractive tourism destinations in many developing and least developed countries. Such under-developed remote villages have full of natural resources, diverse nature in culture, life styles, human skills, talents, etc. Therefore, Community Based Tourism (CBT) has emerged as an alternative type of tourism to utilize such diverse tangible and intangible resources possessed with the rural tourism destinations by taking into account the unique demands of the visitors and provide them with differentiated and diversified tourism products and services. CBT is known as the tourism activities conducted by the local community in a rural area (Anuar \& Sood, 2017) and involves community participation and aims to generate benefits for local communities in the developing world by allowing tourists to visit these communities to receive an exciting experience and learn. Due to its nature, the developing and least developed countries (LDCs) emphasized that the CBT as a poverty reduction, sustainability improvement and community development tool that strengthens the ability of rural communities to manage tourism resources while ensuring the local community's participation towards initiating and sustaining the tourism business activities (Dangi \& Jamel, 2016; UNWTO, 2017).

The closer look at the definitions of CBT shows that, it was built by incorporating the elements of social capital such as community participation, cooperation, sharing the resources and benefits and, subsequently, these were considered as the principals of CBT. Therefore, Capitals Approach to Sustainability in CBT discussed social capital as one of the three forms of capitals and other two were natural capital and human capital (Lehtonen, 2004). Hence, CBT empowerment projects which were initiated in many countries have emphasized to backup and strengthen the community in terms of human capital and social capital and assist them to harness the opportunities from proper utilization of natural capital while protecting those for the future uses. CBT usually focuses on niche markets by offering the tourism products and services in the range of eco-tourism, agritourism, adventure tourism, cultural and heritage tourism and specifically draws the attention on offering the local products and services to customers while spreading the economic benefit among the community (ASEAN 
Community Based Tourism Standard, 2016). Hence, one of the goals of the CBT projects is to empower the tourism community to act towards a collective goal (Rodriguez-Giron \& Vanneste, 2019). The role of social capital is must in sharing the human capital have with the community people as well as the natural capital available in the destination. The community empowerment approach is doing an intervening role for building and maintaining social capital and improving collective wellbeing among the community people in the tourism destinations with the purpose of helping them to achieve success and sustainability in tourism businesses.

However, in many of the rural destinations, in the historical era, cohesiveness, cooperativeness and mutual sharing were the characteristics in their day-to-day life. For example, as shown by Alawattage et al. (2016), prior to the advent of microfinancing projects for poverty eradication in rural areas of Sri Lanka, the village women have traditionally gathered as small kinship groups to work together informally and to pool their cash, called 'Auction ciettu' system. This system was successfully operated as small micro-borrowing groups around blood relationships and close personal friendships. These traditional systems were eroded by such development projects like formal microfinance projects which were promoted as tools for rural level poverty alleviation. On the other hand, with the commercialization due to opening up the livelihood opportunities in the tourism sector, presently, several community people work alone to maximize the benefits for their own while others work collaboratively under the facilitation arm of CBT projects or any other development initiatives to harness the vast opportunities rather they could reach by working alone. Also, past researchers viewed upon (for example, Rodriguez-Giron \& Vanneste, 2019; Putnam, 1995), directing the community for a common goal and collective action and also for sharing resources seem difficult because of such diverse interests, selfreliant nature, and competitive behaviour of the community people. Hence, the role of third party which works as development initiatives, for instance, CBT projects, cluster or value chain developers or aid agencies, etc. require to be taken the leading role of initiating to develop social capital among the community and guiding them for better results. However, as elaborated above, all the MSSTEs who operate in rural tourism destinations do not create such community clusters, networks or associations and they practice unaccompanied behaviour. Therefore, a dilemma is there about whether this rural community either who were empowered or not empowered has the capacity to act together to shape a common future and self- 
determine its own development path (Rodriguez-Giron \& Vanneste, 2019). Therefore firstly, this paper endeavor to reveal the impact of social capital geared by the CBT projects among the community people on the success of micro and smallscale tourism entrepreneurs (MSSTEs) in rural tourism destinations and next to determine is there any distinction of the variation created in the business success by the construct of social capital between the MSSTES who were empowered and who were not empowered. Moreover, several categories of social capital such as structural social capital, relational social capital and cognitive social capital were discussed in the past literature. Moreover, a debate is still continuing regarding which type of social capital does affect highly on the business success of the tourism businesses (Minamoto, 2010; Pramanik et al., 2019; Zhang et al., 2020) and the third objective of this study was focused on this predicament.

\section{LITERATUR REVIEW}

Past research has identified social capital as an integral part of the community-based tourism because the active participation of social actors in the destination is must for the success and sustainability of CBT. Social capital concept was first introduced by Bourdieu in 1983 and Coleman incorporated further views on social capital concept in 1988. Coleman argued that social capital consisted of mutual trust, authority relations, information potential, effective norms, and appropriate social organizations. In 2000, Putnam, further contributed to the Coleman's views on social capital concept (Pramanik et al., 2019). Putnam (1995) defined social capital as the capacity of people to act together towards common goals. Social capital is defined by the OECD (2001, p. 103) as "networks together with shared norms, values and understandings that facilitate cooperation within or among groups". Social capital is most frequently defined in terms of the groups, networks, norms, and trust that people have available to them for productive purposes.

The dimensions of social capital revealed in the past literature are also vary from study to study. In 1988, Coleman argued that social capital consisted of mutual trust, authority relations, information potential, effective norms, and appropriate social organizations. Putnam (1995) presented trust, networking, and norms of reciprocity as the dimensions. Pramanik et al. (2019) used two dimensions of social capital including 'role of trust' and 'collective action'. Zhang et al (2020) presented six dimensions including: collective efficacy, community belongingness, traditional social regulations, community cohesion, social network, and community competency. So, social capital is considered as multi-dimensional 
in nature specifically regarding CBT and cluster approaches of Micro, Small and Medium Scale Enterprises (Claridge,2018; Andrews, 2010; Grootaert et al., 2003). These multi-dimensions of social capital in community development research context have been categorized into three meaningful groups as structural, relational and cognitive social capital (Nahapiet \& Ghoshal, 1998). Andrews (2010) defined structural social capital as the presence of a network of access to people and resources, relational social capital as the feelings of trust that are shared by the many actors within the social context such as group, organization, and community, and cognitive social capital as the subjective interpretations of shared understandings. However, their argument was that social capital have mostly focused on structural and relational social capital and very limited on cognitive social capital. Claridge (2018) also presented a similar definitions and structural social capital was considered as connections among actors, relational social capital as trust between actors, and cognitive social capital as shared goals and values among actors. A little bit similar view was presented by Rodriguez-Giron \& Vanneste (2019, p.33) and identified three key dimensions in social capital as networks (structural input), norms and trust (cognitive input/output), and collective actions (results output) and these three were considered as the building blocks of social capital relating to CBT. Only two categories of social capital: structural and cognitive social capital were considered by Grootaert et al. (2003). Types of groups and networks that poor people can call upon, the nature and extent of their contributions to other members of those groups and networks were discussed as structural social capital and the respondents' subjective perceptions of the trustworthiness of other people and key institutions that shape their lives as well as the norms of cooperation and reciprocity that surround attempts to work together to solve problems were discussed under the category of cognitive social capital. Further, this study explored 6 sub dimensions under these two categories of social capital including Groups and Networks, Trust and Solidarity, Collective Action and Cooperation, Information and Communication, Social Cohesion and Inclusion, and Empowerment and Political Action (Grootaert et al., 2003, P.5). The Social Capital Assessment Tool (SOCAT) that was developed by the World Bank also utilized three dimensions of social capital including structural social capital, cognitive social capital, and collective action. Number of social organizations and networks, member characteristics, intraorganizational decision-making functions and leadership, relationships with other 
organizations, etc. were the sub indicators of measuring the structural social capital. "Solidarity", "trust and cooperation", and "conflict resolution methods" were the indicators of measuring cognitive social capital and type of collective action, the outcome of such activity, and people's motivation to participate were used as indicators to measure the "collective action" by the SOCAT. By doing a research on post-tsunami recovery among community clusters, Minamoto (2010 P.550) expressed that structural social capital is tangible and easily understood and it represents regional organizations, interpersonal networks, community-based organizations, and the like. On the other hand, cognitive social capital includes trust, norms, and values and all of those are born of people's interactions with each other. The review of past literature on social capital dimensions relating to community-based tourism revealed that majority of researchers emphasized on structural and cognitive social capital and few studies have focused on the relations social capital or collective action. Also, several studies incorporated the relational and cognitive social capital and therefore, less emphasis was there on relational social capital.

Past literature has discussed both positive and negative effects of the impact of social capital on community-based tourism. Social capital enables to create a solidarity or cohesion among community members which reinforce social support and social networks among local residents and families and thereby building successful tourism businesses (Zhang et al., 2020; Rodriguez-Giron \& Vanneste, 2019; Nunkoo, 2017), create a sense of identity and common purpose among community members and reduces social inequality between communities (Nunkoo, 2017), improve residents' interests in community issues and increases responsibility and accountability among the community (Zhang et al., 2020; Pramanik et al., 2019), assist in improving human capital of the community such as community competency and knowledge, problem-solving ability of local residents that arise through such collective efforts and ultimately this affects to have with the community a knowledge to practice sustainability by covering environmental, economic and social aspects (Zhang et al., 2020; Pramanik et al., 2019), build community culture and important values (Zhang et al., 2020), reinforce relationships and interactions among people in the community (Zhang et al., 2020; RodriguezGiron \& Vanneste, 2019; Minamoto, 2010; Moscardo, 2013). Further, social capital facilitates for knowledge sharing and innovation (Kim \& Shim, 2018; Martínez-Pérez et al., 2016), stimulates open and 
efficient exchange of information and resources among the businesses and community people (Inkpen and Tsang, 2005). Shanmuganathan et al. (2020) pointed out the findings of Thammajinda (2013) and Hwang (2012) says that social capital opens the opportunity for funds, advisory services, technical support and skill development for the local people at the grass-root level and this affects to enhance peoples' involvement in the tourism industry. Lin et al. (2017) found that in Sri Lankan context, though both rural and urban residents believe about future tourism development, among the urban community impact of social capital is insignificant in future tourism development. By citing the findings of several researchers (Blackman \& Henderson, 2004; De Smedt et al., 2013; Slaughter, 2002; Wilkinson et al., 2014) who did a survey of empowered farmer communities in rural settings, Bourgeoisa et al. (2017) highlighted that foresight initiative supporting was provided as part of an empowerment for the community to work as change agents in the society by working collaboratively for shaping and developing their future.

Also, several researchers found that bad relationships create negative results among the community such as lack of infrastructure development, lack of competent and trained people in the community, poor marketing and destination promotion, absence of equitable sharing of resources, etc. (Pramanik et al., 2019; Payne et al., 2011). However, it is not having a concluding view of whether such positive effects or bad effects foreseen relating to either with empowered or not empowered MSSTEs. In Sri Lankan context, few researches (for example, Minamoto, 2010; Shanmuganathan et al., 2020; etc.) are available which were focused on social capital aspect of community tourism. However, any evidences on such a comparative analysis between the MSSTEs who were empowered and who were not empowered by any $\mathrm{CBT}$ project as well as which dimensions of social capital affect significantly on business growth cannot be found. Therefore, within that milieu, with the aim of fulfilling knowledge and contextual gaps in the existing research literature, the following three research hypotheses were formulated to test in this study.

$\mathrm{H}_{1}$ : There is a significant difference in the impact of social capital on the business success between the MSSTEs who were empowered by a CBT project and the MSSTEs who were not empowered by any CBT project. $\mathrm{H}_{2}$ : Structural social capital affect significantly on the business success of the MSSTEs who were empowered by a CBT project.

$\mathrm{H}_{3}$ : Cognitive social capital affect significantly on the business 
success of the MSSTEs who were empowered by a CBT project.

\section{METHODS}

Positivism approach was applied in this study because it aims to reveal the impact of social capital on the business success of the micro and small-scale tourism entrepreneurs in Sri Lankan context by recognizing the individual's and group constituents of a phenomenon of business success owing to empowerment and then simplifying the phenomenon in terms of different constructs, and relationships between these constructs. The study constructs included "social capital" as the independent variable and "business success" as the dependent variable. Social capital characteristics that have been empowered by CBT projects among the community tourism entrepreneurs or have with inheritably with the community were identified in this study under two sub categories as 'structural social capital' and 'cognitive social capital' by taking into account the categorization used by the majority of the past researchers (for example: Minamoto, 2010; Andrews, 2010; etc.). The definition presented by Andrews (2010) was used in this study for defining the two dimensions of social capital. The structural social capital is defined as the presence of a network of access to people and resources. Four statements as per 5-point Likert scaled $(5=$ Strongly agree to $0=$ Strongly Disagree) were used in measuring the degree of structural social capital (SSC) possessed with the community people of the research sample. Those include: i). Wellfunctioning the established CBOs in the village $\left(\mathrm{SSC}_{1}\right)$; ii). Possessing strong networks to get the assistance and required services from the outside $\left(\mathrm{SSC}_{2}\right)$; iii). Having a greater contribution to other members of the group $\left(\mathrm{SSC}_{3}\right) ; \quad$ and iv). Regular gatherings as a group stimulate problem solving and mutual assistance $\left(\mathrm{SSC}_{4}\right) . \quad$ Cognitive social capital is defined as the capability for resource exchange and it covers shared goals, norms and values among actors as well as trust, solidarity and reciprocity. 5-point Likert scaled five statements were used in measuring the degree of cognitive social capital (CSC) possessed with the community people. Those include: i). Having common vision, mission, and goals direct the community work collaboratively $\left(\mathrm{CSC}_{1}\right)$; ii). Values and norms of the society facilitate work together and solve problems $\left(\mathrm{CSC}_{2}\right)$; iii). Equality in sharing resources and benefits stimulate uplifting the tourism in the village $\left(\mathrm{CSC}_{3}\right) ; \quad$ iv). Trustworthiness of the village leadership and other people shape their lives for better living $\left(\mathrm{CSC}_{4}\right)$; and v). Uniformity in service standards, pricing and branding the tourism products among the community enhance more tourist attraction $\left(\mathrm{CSC}_{5}\right)$. 
Pre-tested

structured

questionnaire was used to reveal the respondents' perception on the impact of social capital on tourism business success. As considered by the past researchers (Gunarathne, 2008; Freel \& Robson, 2004; Storey et al., 1987), the business success was considered as a summated measure by incorporating three criteria including number of visitors, number of employees and capital investment and aggregated average increase relating to three-year period from 2017 to 2019 was taken into account. The formula for calculating business success was adopted from the measure of business growth which was used by the countries of Organization for Economic Co-operation and Development (OECD, 2000, P. 16).

A sample of 225 micro and small-scale tourism entrepreneurs (MSSTEs) were selected by using the stratified simple random sampling technique from the population of villagers who run the business in rural tourism destinations in Southern and Eastern Provinces of Sri Lanka which were registered under the Sri Lanka Tourism Development Authority or Local Divisional Secretariate. Two strata were identified as the MSSTEs who were empowered by a CBT project and who were not empowered by any CBT project. Accordingly, MSSTEs from Panama and Arugam Bay villages in Ampara district who were empowered by the CBT project of International Labour Organization (ILO) and MSSTEs from Kanneliya, Vihrahena, Mederipitiya and Godahena villages in Galle and Matara districts who were empowered by the CBT project of Ruhunu Tourism Bureau (RTB) were identified as one stratum. Both these CBT projects operate under the Sri Lanka Tourism Development Authority. The other stratum included MSSTEs from the villages of Okanda, Panama, Hikkaduwa, Koggala, Mirissa, Dondra, and Kalametiya in both Southern and Eastern provinces of Sri Lanka who were not empowered by any CBT project. Because of nonresponding and missing data, 25 questionnaires were rejected and 200 questionnaires were proceeded for analysis purpose. Out of these, 130 were the empowered MSSTEs and the remaining 70 were nonempowered MSSTEs. The response rate was about 89 percent. Cronbach alpha test was used to determine the internal consistency of the measurements used in the study and the reliability of the multiple Likert Scale questions in the questionnaire. Independent sample T-Test, correlation and regression analysis were applied for data analysis and hypotheses testing. As pointed out by Hair et al., (2014, p. 11) with a moderate effect size power reaches acceptable levels at sample sizes of 100 or more for alpha levels of both .05 and .01. Because the 
sample size of this study is more than 100 , alpha levels of both .05 and .01 have been selected in testing hypotheses.

\section{RESULTS}

As per the basic profile of the sample, $60 \%$ of the MSSTEs was male and $40 \%$ was female, $79 \%$ was married ones. Majority $(95 \%)$ was in the age group of $30-50$ years and $62 \%$ has received at least senior secondary level education and $21 \%$ has tertiary level education. The most popular tourism activities among the community people in the selected villages are: operate homestays, restaurants, souvenir shops and retail shops; conduct cookery classes; arrange safari tours (Wildlife, village life, heritage and boat tours), adventure activities (land and water based) surfing and surfing training, beach party and cultural entertainments, and tour guiding. As shown in Table 1, Cronbach's alpha values for the two dimensions of social capital reported as greater than 0.7. As per the rule of thumb of internal consistency described by Hair et al (2014) and Zikmund (2013), this assures the internal consistency and the scales deemed reliable for further analyses.

Table 1: Results of Reliability Test

\begin{tabular}{|l|l|c|}
\hline \multicolumn{1}{|c|}{ SC Dimensions } & \multicolumn{1}{|c|}{ Indicators } & Cronbach's alpha \\
\hline Structural SC & $\mathrm{SSC}_{1}, \mathrm{SSC}_{2}, \mathrm{SSC}_{3}, \mathrm{SSC}_{4}$ & 0.796 \\
\hline Cognitive SC & $\begin{array}{l}\mathrm{CSC}_{1}, \mathrm{CSC}_{2}, \mathrm{CSC}_{3}, \mathrm{CSC}_{4}, \\
\mathrm{CSC}_{5}\end{array}$ & 0.812 \\
\hline
\end{tabular}

Source: Survey- 2019/2020

The first hypothesis of this study $\left(\mathrm{H}_{1}\right)$ assumed that "There is a significant difference in the impact of social capital on the business success between the MSSTEs who were empowered by a CBT project and the MSSTEs who were not empowered by any CBT project. The impact of social capital on business success was revealed through T-Test results depicted in
Table 2 and Table 3. As shown in Table 2, consequently the mean value relating to the empowered MSSTEs and the non-empowered MSSTEs was reported as 71. 37 and 47.86. This implies that MSSTEs who received the empowerment assistance, on average, possess higher level of social capital attributes than those who have not received any empowerment. 
Table 2: Descriptive Statistics relating to the MSSTEs

Source: Survey- 2019/2020

\begin{tabular}{|c|c|c|c|c|}
\hline & Empowered/Not & $\mathrm{N}$ & Mean & SD \\
\hline Degree of SC & No & 70 & 47.86 & 1.00 \\
\hline & Yes & 130 & 71.37 & 1.67 \\
\hline
\end{tabular}

As per the T-Test results shown in Table 3, $P$-value $(0.002)$ was less than .05 and the two variances are significantly different. By looking down the Equal variances not assumed column it can be seen that the group means are significantly different as the value in the "Sig. (2-tailed)" row is less than 0.05 . This implies that there is a significant difference in impact of social capital on the business success between the MSSTEs who were empowered and not empowered by a CBT project. Hence, the first hypothesis $\left(\mathrm{H}_{1}\right)$ of this study can be accepted.

Table 3: T-Test Results for Social Capital and Business Success

\begin{tabular}{|c|c|c|c|}
\hline & \multicolumn{2}{|c|}{ Social Capital Attributes } \\
\hline & & $\begin{array}{c}\text { Equal } \\
\text { variances } \\
\text { assumed }\end{array}$ & $\begin{array}{c}\text { Equal } \\
\text { variances not } \\
\text { assumed }\end{array}$ \\
\hline $\begin{array}{l}\text { Levene's Test for } \\
\text { Equality of } \\
\text { Variances }\end{array}$ & $\begin{array}{l}\text { F } \\
\text { Sig. }\end{array}$ & $\begin{array}{c}10.183 \\
.002\end{array}$ & \\
\hline & $\begin{array}{l}t \\
d f \\
\text { Sig. (2-tailed) } \\
\text { Mean Difference } \\
\text { Std. Error Difference } \\
\text { 95\% Confidence Interval } \\
\text { Lower } \\
\text { of the Difference } \\
\text { Upper }\end{array}$ & $\begin{array}{c}-8.159 \\
128 \\
.000 \\
-23.508 \\
2.36033 \\
-24.64172 \\
-15.29356\end{array}$ & $\begin{array}{c}-8.393 \\
120.65 \\
.000 \\
-23.508 \\
2.7036 \\
-24.46634 \\
-15.47141\end{array}$ \\
\hline
\end{tabular}

Source: Author survey - 2019/20 
Third objective as well as second and third hypotheses were focused on determining which type of social capital either structural or cognitive does affect highly on the business success of the tourism businesses. The second hypothesis of this study $\left(\mathrm{H}_{2}\right)$ was "Structural social capital affect significantly on the business success of the MSSTEs who were empowered by a CBT project" and third hypothesis $\left(\mathrm{H}_{3}\right)$ was "Cognitive social capital affect significantly on the business success of the MSSTEs who were empowered by a CBT project". MSSTEs in the sample who were empowered by a CBT project were only utilized for testing these hypotheses. As per correlation statistics depicted in Table 4, both structural social capital and cognitive social capital have high level of positive correlations respectively 0.717 and 0.693 with the business success. This implies that both CBT projects (ILO and RTB) assisted in improving both dimensions of social capital among the selected MSSTEs and the social capital attributes show a high level of positive correlation with the business success. Table 5 depicts the overall model summary of the multiple regression analysis on the two dimensions of social capital of MSSTEs with business success. $\mathrm{R}$ square value of 0.606 indicates that $60.6 \%$ of variance in business success of MSSTEs who were empowered by a CBT project was significantly explained by the structural and cognitive social capital.

Table 4: Correlation statistics of Social capital and Business success

\begin{tabular}{|l|l|c|c|c|}
\hline & & $\begin{array}{c}\text { Business } \\
\text { Success }\end{array}$ & $\begin{array}{c}\text { Structural } \\
\text { Social Capital }\end{array}$ & $\begin{array}{c}\text { Cognitive social } \\
\text { capital }\end{array}$ \\
\hline $\begin{array}{l}\text { Pearson } \\
\text { Correlation }\end{array}$ & Business Success & 1.000 & .717 & .693 \\
\cline { 2 - 5 } & $\begin{array}{l}\text { Structural Social } \\
\text { Capital }\end{array}$ & .717 & 1.000 & .677 \\
\cline { 2 - 5 } & $\begin{array}{l}\text { Cognitive social } \\
\text { capital }\end{array}$ & .693 & 677 & 1.000 \\
\hline
\end{tabular}

Source: Author survey - 2019/20 
Table 5: Model Summary

\begin{tabular}{|l|c|c|c|l|}
\hline Model & $\mathrm{R}$ & $\mathrm{R}^{2}$ & $\begin{array}{c}\text { Adjusted } \\
\mathrm{R}^{2}\end{array}$ & $\begin{array}{l}\text { Std. Error } \\
\text { of the } \\
\text { Estimate }\end{array}$ \\
\hline $\begin{array}{l}\text { Degree of Social capital of the } \\
\text { MSSTES }\end{array}$ & $.779^{\mathrm{a}}$ & .606 & .589 & 12.48417 \\
\hline
\end{tabular}

a. Predictors: (Constant), SSC, CSC

Further, multiple regression coefficients which depict in Table 6 show that the two selected dimensions of social capital affect significantly on the business success of the community who were empowered by the two CBT projects in the selected villages. As per the Beta value under Standardized Coefficients column, the highest number in the beta is 0.489 relating to structural social capital. Cognitive social capital shows the second highest impact by reporting the beta value of 0.390 . The $P$ values show that the impact of both of the social capital dimensions of MSSTEs on business success was significant at the 0.01 level and therefore, the hypothesis two and three can be accepted. This implies that the empowerment efforts of the CBT projects for enhancing either structural type social capital or cognitive type social capital are the good predictors of business success of the rural community people in tourism attraction areas because both of these create $60.6 \%$ variation in business growth.

Table 6: Coefficients

\begin{tabular}{|l|c|c|c|c|c|}
\hline Model & \multicolumn{2}{|c|}{$\begin{array}{c}\text { Unstandardized } \\
\text { Coefficients }\end{array}$} & $\begin{array}{c}\text { Standardized } \\
\text { Coefficients }\end{array}$ & $\mathrm{t}$ & Sig. \\
\cline { 2 - 7 } & $\mathrm{B}$ & $\begin{array}{l}\text { Std. } \\
\text { Error }\end{array}$ & Beta & & \\
\hline Structural Social Capital & .577 & .091 & .489 & 6.320 & .000 \\
\hline Cognitive Social Capital & .471 & .092 & .390 & 5.143 & .000 \\
\hline
\end{tabular}

a. Dependent Variable: Business success 


\section{DISCUSSION}

As emphasized by many past researchers (for example: Zhang et al., 2020; Rodriguez-Giron \& Vanneste, 2019; Pramanik et al., 2019), this study also revealed that social capital empowered by the CBT projects affect to enhance the business success of community tourism entrepreneurs. As found in this study, past researchers (Zhang et al., 2020; Rodriguez-Giron \& Vanneste, 2019; Minamoto, 2010; Moscardo, 2008) also identified social capital as an integral part of the communitybased tourism because the active participation of social actors in the destination is must for the success and sustainability of CBT. Precisely in this study, the structural type social capital affect highly on the business success than the cognitive type of social capital. Past researchers, for example, Rodriguez-Giron \& Vanneste (2019) and Putnam (1995), explained that because of diverse interests, self-reliant nature, and competitive behaviour of the community people it is difficult to direct the community for a common goal, collective action, and towards sharing resources. The respondents in the sample, believed that regular gathering to discuss and solve the problems, strong intra-networks, internetworks and external networks to get the assistance and required services are essential for achieving higher level of business success. A similar view was presented by several researchers including: Zhang et al., (2020); Pramanik et al., (2019); Zhang et al., (2020); Pramanik et al., (2019); and Nunkoo, (2017). In line with the finding of Grootaert et al. (2003), it was founded that trust, solidarity and reciprocity affect for continuation of the CBOs in the selected tourism villages and shared norms and values among actors ensure the sustain in the business. As founded by Zhang et al. (2020) and Pramanik et al. (2019), this study also revealed that the norm of equality and sharing benefits were believed as very essential to active participation for community development and tourism business success. Specifically, the contribution made by the members of the CBT societies for the community tourism development fund and equitably sharing the benefits show the trustworthiness and commitment of the community. This further proved by comparing the impact of social capital on business growth between the micro and small-scale tourism entrepreneurs who were empowered and who were not empowered by a CBT project and findings revealed that significant difference exists in impact of social capital on business success between the empowered and nonempowered MSSTEs.

\section{SIGNIFICANCE OF THE STUDY}

Findings of this study contributed to determine the significant role 
of the CBT projects on empowering the social capital attributes further among the community people who involved in diverse tourism business activities in rural tourism destinations. Though the inherited nature and traditional way of living of the rural people demonstrate several social capital attributes, the paradigm shift from such traditions and values due to increasing the competition and more value for the uniqueness of their products and services cause to raise the requirement of the third-party intervention to streamline and strengthen the collective behaviour to reach the success. This was proved as per the findings of demarcation exist in the business success between the MSSTEs who were empowered and not empowered by a CBT project. Further, the findings are supportive for determining the role of extension of the CBT projects in terms of enhancing the social capital among the community tourism entrepreneurs. Both structural and cognitive social capital affect significantly on the business success while structural capital shows more power to create a variance on business success than cognitive social capital. This implies that tangible social capital attributes such as wellfunctioning of community associations, strong interpersonal and institutional networks, regular gathering, etc. are perceived as very important for business success. Providing objective assessment about what we have relating to social capital such as network of access to people and resources need to be promoted by the CBT projects rather the subjective assessments such as establishing shared goals, norms and values among actors as well as trust, solidarity and reciprocity. Main limitation of this study was selecting only two CBT projects which were operated in the selected few villages from Ampara, Marara and Galle districts of Sri Lanka. Future researchers could extend the focus on social capital and business growth by extending such research into other tourism destinations in Sri Lanka which were empowered by other CBT projects.

\section{CONCLUSION}

Community Based Tourism as an alternative approach to Mass tourism, is known as the tourism activities conducted by the local community. Therefore, social capital possessed with the community is considered as essential for the proper implementation of this participatory development approach. Though the rural society people had with several inherited social capital attributes like mutual support, sharing resources, working for a common goal, etc., the self-reliant nature and competitive behaviour of the community people seem to play as more prominent among the rural community in present context. Hence, the involvement 
of third party for promoting and continuing the social capital attributes among the rural tourism community has been identified as essential to the business growth of MSSTEs. One of the research objectives and a hypothesis of this study focused on revealing this and findings discovered that a significant variation of the business success was created by the social capital. The results relating to the comparison of the impact of social capital on the business success between the MSSTEs who were empowered and who were not empowered by any CBT project/s revealed that a greater difference exists between the empowered and unempowered MSSTEs. Therefore, it can be concluded that empowerment efforts for promoting social capital attributes among the MSSTEs will assist them to reach higher level of business growth. Further, this study was focused on determining which type of social capital dimension either structural capital or cognitive social capital affect highly on the business success of the MSSTEs. As per the findings, it can be concluded that structural type social capital including strong networks, proper functioning of community societies and associations, etc., affect significantly on the business success rather than the cognitive type social capital which emphasized subjective feelings like trust, norms, reciprocity, etc. However, both types of social capital affect significantly on the business success of the MSSTES in the sample and a highly valuable role is doing by both the CBT projects towards ensuring the success of the community tourism businesses by strengthening the social capital attributes among the tourism entrepreneurs in the rural tourism destinations.

\section{REFERENCES}

Alawattage, C., Graham, C. \& Wickramasinghe, D. (2019). Micro accountability and biopolitics: Microfinance in a Sri Lankan village, Accounting, Organizations and Society, ELSEVIER, 72, 38-60,

https://www.sciencedirect.co $\mathrm{m} /$ science/article/abs/pii/S03 61368218302642

Andrews, Rhys. (2010). Organizational Social Capital, Structure and Performance, Human Relations 63(5), 583-608.

Anuar, A. N.A, \& Sood, N. A. A. M. (2017). Community based tourism: Understanding, benefits and challenges. Journal of Tourism \& Hospitality, 6(1), 1000263. https://doi.org/10.4172/2167$\underline{0269.1000263}$

ASEAN Community Based Tourism Standard. (2016). Jakarta: ASEAN Secretariat, January, 2.

Bourgeoisa, B., Penuniab, E., Bishtc, S., \& Boruk, D. 
(2017). Foresight for all: Coelaborative scenario building and empowerment, Technological Forecasting and Social Change, Elsevier, $124(C)$, 178-188. https://repository.up.ac.za/bit stream/handle/2263/63184/B ourgeois_Foresight_2017.pdf

Claridge,T. (2018). Dimensions of Social Capital - structural, cognitive, and relational, Social Capital Research, January, https://www.socialcapitalrese arch.com/structuralcognitive-relational-socialcapital

Dangi, Tek B., Tazim Jamal. (2016). An Integrated Approach to Sustainable Community Based Tourism. Journal of Sustainability. 8, 475, doi:10.3390/su8050475

Freel, M. S., and Robson, P. J. A. (2004). Small firm innovation, growth, and performance. International Small Business Journal, 22 (6), 561-575.

Grootaert, C., Narayan, D., Nyhan Jones, V., \& Woolcock, M. (2003). Measuring Social capital, An Integrated Questionnaire, The World Bank, Washington, D.C.

https://www.researchgate.net/ publication/292502553

Gunarathne, K. A. (2008). Conceptualizing a model to promote post start-up small business growth in Sri Lanka, Doctoral Thesis epublication, [Accessed on 15.06.2018].

Hair, J. F., Black, W. C., Babin, B. J., \& Anderson, R. E. (2014). Multivariate data analysis, Harlow. UK: Pearson Education Limited.

Inkpen, A. C., \& Tsang, E. W. K. (2005). Social Capital, Networks, and Knowledge Transfer. The Academy of Management Review, 30(1), 146-165. https://doi.org/10.2307/2015 9100

Kim \& Shim, (2018). Social capital, knowledge sharing and innovation of small- and medium-sized enterprises in a tourism cluster, International Journal of Contemporary Hospitality Management, 30(6), 2417-2437, www.emeraldinsight.com/09 59-6119.htm.

Lehtonen, M. (2004). "The Environmental-Social Interface of Sustainable Development: Capabilities, Social Capital, Institutions", Ecological Economics 49 (2): 199-214.

Lin, L.I., Gamage, S.K.N., Ihtisham ul H. A. Q., Nedelea, A.M. (2017). Does social capital influence resident's attitudes towards tourism development in Sri Lanka? Journal of Tourism - 
Studies and Research in Tourism,22, January, https://www.researchgate.net/ publication/312021584

Martínez-Pérez, A., GarciaVillaverde, P. M., Elchi, D., \&. Parra Requena, G. (2016). Cultural Tourism Clusters: Social Capital, Relations with Institutions, and Radical Innovation, Journal of Travel Research, June, https://www.researchgate.net/ publication $/ 325664368$

Minamoto, Y. (2010). Social capital and livelihood recovery: Post-tsunami Sri Lanka as a case, Disaster Prevention and Management, 19(5).

https://www.emerald.com/ins ight/publication/issn/09653562

Moscardo, G., Schurmann, A., Konovalov, E., \& McGehee, N.G. (2013). Using Tourism to Build Social Capital in Communities: New Pathways to Sustainable Tourism Futures, BEST EN Think Tank XIII Engaging Communities in Sustainable Tourism Development, 219236.

Nahapiet, J., \& Sumantra, G. (1998). Social Capital, Intellectual Capital, and the Organizational Advantage, Academy of Management Review 23(2/), 242.

Nunkoo, R. (2017). Governance and sustainable tourism: what is the role of trust, power and social capital. Journal of Destination Marketing and Management 6 (4), 277-285, https://www.academia.edu.

OECD (2000), High Growth SMs and Employment, OECD Publications, 16, https://www.oecd.org/industr y/smes/2493092.pdf.

OECD (2001). The Well-Being of Nations: The Role of Human and Social Capital, OECD, Paris, 103.

Pramanik, P.D., Ingkadijaya, R., \& Achmadi, M. (2019). The Role of Social Capital in Community Based Tourism, Journal of Indonesian Tourism and Development Studies, 7(2) April, 62-75, http://jitode.ub.ac.id.

Payne, G. T., Moore, C. B., Griffis, S. E., \& Autry, C. W. (2011). Multilevel challenges and opportunities in social capital research. Journal of Management, 37(2), 491-520.

Putnam, R. D. (1995) 'Tuning In, Tuning Out: The Strange Disappearance of Social Capital in America', PS: Political Science and Politics, 28(4): 664-83.

Rodriguez-Giron, S., \& Vanneste, D. (2019). Social capital at the tourist destination level: Determining the dimensions to assess and improve collective action in tourism, 
Tourist Studies, 19(1), 2342., journals.sagepub.com/home/t ou.

Shanmuganathan, K., Abeysekera, N., Gamini, L.P.S., \& Chandralal, L. (2020). Linking social capital and people's involvement in the tourism context of Sri Lanka: Special Reference to the Mirrisa, Galle district, Conference Proceedings, 3rd Research Conference on Business Studies (RCBS), 402-406, Vavuniya Campus of the University of Jaffna, Sri Lanka,.

Storey, D. J., Keasey, K., Watson, R., \& Wynarczyk, P. (1987). Performance of small businesses: Profits, jobs, and failure. London: Croom Helm.

UNWTO Annual Report, (2017). e-Library, https://www.eunwto.org/doi/book/

Yang Zhang, Yu Xiong, Timothy J. Lee, Min Ye, \& Robin Nunkoo. (2020). Sociocultural Sustainability and the Formation of Social Capital from Communitybased Tourism, Journal of Travel Research, 1 (14), journals.sagepub.com/home/j tr.

Zikmund, William G., Jon C. Carr, Barry Babin, and Mitch Griffin. (2013), 'Business research methods', Nelson Education. 